\title{
A pesca do pacu (Cuvier, 1818) (Characiformes: Characidae) desembarcado no mercado pesqueiro de Porto Velho (Rondônia), no período de 1985-2004
}

\author{
Carolina Rodrigues da Costa Doria \\ Maria Alice Leite Lima* \\ Laboratório de Ictiologia e Pesca, Departamento de Biologia, Universidade Federal de Rondônia (UNIR) \\ BR: 364, Km 9,5, CEP: 78900-000, Porto Velho - RO, Brasil \\ *Autor para correspondência \\ alicelima2003@yahoo.com.br
}

\section{Resumo}

O presente estudo avaliou aspectos da pesca do pacu (Mylossoma spp., Myleus spp., Metynnis spp.) desembarcados no mercado pesqueiro Flutuante Cai N'água (Porto Velho, RO), no período de 1985 a 2004 , verificando variações inter e intra-anuais da produção, variações nos comprimentos em centímetros e características gerais da pesca. A produção anual variou de $33.000 \mathrm{~kg}$ a $146.000 \mathrm{~kg}$ (média $=86.585 \mathrm{~kg}$ ), representando $6,63 \%$ a $20,45 \%$ do total das espécies desembarcadas no período estudado. Essas variações acompanharam o ciclo hidrológico, apresentando maior produção em anos subseqüentes às cheias intensas. A produção mensal variou de $0 \mathrm{a} 42.366 \mathrm{~kg}$ (média $=5.772 \mathrm{~kg}$ ) e esteve relacionada às migrações reprodutivas. $\mathrm{O}$ pacu apresentou oscilações de comprimento padrão de 14 a $20 \mathrm{~cm}(18,72 \mathrm{~cm} \pm 3,69)$. A pesca foi baseada no uso de redes de lance e malhadeiras, onde os principais ambientes de captura foram os rios afluentes do baixo rio Madeira (Jamari, Oropiara, Machado e Novo Aripuanã). A CPUE calculada entre os anos de 2003 e 2005 foi de $15 \mathrm{~kg}_{\text {.pescador }}{ }^{-1}$. $\operatorname{dia}^{-1}( \pm 21)$. Os resultados mostram que a categoria constituiu no período um importante recurso para a exploração comercial local, como verificado para outras regiões da Amazônia.

Unitermos: Myleus, Metynis, Mylossoma, rio Madeira, Amazônia

\section{Abstract}

Pacu fish (Cuvier, 1818) (Characiformes: Characidae) landed in Porto Velho (Rondônia) fish market from 1985 to 2004. This study evaluated various aspects of the profile of pacu (Mylossoma spp., Myleus spp., Metynnis spp.) fish marketed on the Cai N'água floating platform of Porto Velho (RO) from 1985 to 2004. Inter- and intra-annual variations in yield, variation in fish length and general characteristics of the fishing are reported. The annual pacu yield ranged from $33,000 \mathrm{~kg}$ to $146,000 \mathrm{~kg}$ (average $=86,585 \mathrm{~kg}$ ), representing from $6.6 \%$ to $20.45 \%$ of the total landings in the studied period. These variations followed the hydrologic cycle, and the greatest yields were recorded in the years following the highest water levels. The monthly production ranged from 0 to $42,366 \mathrm{~kg}$ (average $=5,772 \mathrm{~kg}$ ) and it was related to reproductive migration. The pacu presented variations in standard length from 14 to $20 \mathrm{~cm}(18.72 \mathrm{~cm} \pm 3.69$, mean $\pm \mathrm{sd}$ ). The fishing was based on the use of seines and gill nets and the main environments of capture were tributaries of the low Madeira River (Jamari, Oropiara, Machado and Novo Aripuanã). The CPUE calculated for 2003 to 2005 was $15 \mathrm{~kg}^{*}$ fisherman- 
${ }^{1}$ day $^{-1}(\mathrm{sd}= \pm 21)$. The results show that the category constituted during this period an important resource for local commercial exploitations, as verified in other regions of the Amazon.

Key words: Myleus, Metynis, Mylossoma, Madeira River, Amazon

\section{Introdução}

A pesca, como atividade econômica e de subsistência, tem grande importância econômica e social para a Amazônia. É a atividade extrativista tradicionalmente mais importante, representando fonte de proteína animal para a população local e renda, pela sua comercialização (Santos, 1986/87; Petrere Jr., 1992).

A produção pesqueira no estado de Rondônia oscila em 2000 toneladas*ano- ${ }^{1}$ (Santos, 1986/1987) e a produção anual em Porto Velho está em torno de 729 toneladas (Leme, 2005).

Entre as espécies comercializadas, os pacus têm apresentando grande importância relativa, constituindo de 6 a 16\% da produção total do pescado desembarcado no mercado Cai N'água, de 1979 a 2001 (Goulding, 1979; Boischio, 1992; Doria et al., 1998; Brasil de Souza, 2002).

Várias espécies da sub-família Serrassalminae são comercializadas com a denominação de "pacu" no mercado de Porto Velho - RO (Myleus spp.; Mylossoma aureum; Mylossoma duriventre, Metynnis spp.) (observação pessoal). Dentre elas, o pacu manteiga, Mylossoma duriventre, apresenta maior representatividade nos desembarques (observação pessoal).

A ausência de dados específicos e contínuos sobre o esforço de pesca, requisitos essenciais para a avaliação de estoques, relatada em toda a Amazônia (Isaac e Ruffino, 2000a), é acentuada em Rondônia. O que põe em risco a sustentabilidade da pesca.

Neste contexto, o presente trabalho teve como objetivo avaliar o perfil da pesca do pacu, a partir dos desembarques realizados no mercado pesqueiro de Porto Velho (RO) entre 1985 e 2004.

\section{Material e Métodos}

\section{Descrição da área}

O rio Madeira é o principal tributário do rio Amazonas e um dos maiores do mundo, com uma extensão de $3.352 \mathrm{~km}$ (Goulding et al., 2003). É caracterizado pelas águas brancas resultantes do carreamento de sedimento das regiões andina e préandina (Sioli, 1968); uma vez que se trata de um sistema geologicamente jovem, o rio ainda está cavando o seu próprio leito o que, por conseqüência, promove um elevado grau de erosão fluvial. Em decorrência disto, suas águas são altamente turvas, com grandes quantidades de material em suspensão, provenientes do sedimento com origem em materiais vulcânicos, ricos em nutrientes (Goulding et al., 2003).

O rio Madeira é constituído por várias corredeiras em sua parte alta (Goulding, 1979). Apresenta um curso relativamente linear e comporta subunidades geográficas diferenciadas, envolvendo uma parte mais alta, denominada Alto Estrutural Guajará-Mirim/Porto Velho (Souza-Filho et al., 1999) e nas partes média e baixa apresenta áreas típicas de planície de inundação, especialmente à jusante da Cachoeira do Teotônio, principal corredeira do rio (Goulding, 1979).

O mercado pesqueiro de Porto Velho, Cai N'água, é o maior porto do Estado de Rondônia em volume desembarcado e o mais desenvolvido em relação ao tipo de embarcações que nele aportam, bem como a tecnologia de pesca empregada. Compreende metade da produção total do Estado e 4\% de toda a Amazônia. A pesca comercial que abastece este mercado é realizada basicamente nos trechos médio e baixo do rio Madeira, nas áreas típicas de planície de inundação (Santos 1986/87; Leme, 2005).

\section{Obtenção e análise dos dados}

Os dados de produção do pacu em quilos $(\mathrm{kg})$ anual referente aos anos de 1990 e 2004 e produção mensal de 1999 a 2004 foram obtidos de registros da Colônia de Pescadores de Porto Velho (RO) Tenente Santana Z-1 
e de referências bibliográficas. A colônia de pescadores registra diariamente toda a produção pesqueira (produção específica por pescador) desembarcada e comercializada no seu flutuante por pescadores filiados, sobre a qual é cobrada a taxa obrigatória de comercialização do pescado que é destinada a colônia. Estes dados são registrados, e processados e armazenados por funcionários da administração da colônia.

Dados de comprimento padrão $(\mathrm{cm})$ de amostra de exemplares selecionados no momento do desembarque foram registrados diariamente (exceto finais de semana e feriados) por coletores treinados com auxílio de uma trena. A amostragem foi realizada mediante a autorização do pescador e considerou pelo menos 20 exemplares de tamanhos variados do total desembarcado no dia no flutuante Cai N'água e terminal pesqueiro, na cidade de Porto Velho. Foram feitas análises da estrutura do comprimento nos anos de 1997, 2001 e 2004. Estes dados são apresentados na forma de histogramas.

As curvas de variações do nível hidrológico do rio Madeira foram obtidas na Estação Portobrás, localizada em Porto Velho, pela Companhia de Pesquisas em Recursos Minerais (CPRM) da cidade. Posteriormente, foram relacionadas à produção anual e mensal da categoria pacu.

Através de entrevistas realizadas com pescadores selecionados aleatoriamente nos desembarques referente ao período de novembro de 2003 a fevereiro de 2005, foram obtidos os dados de esforço pesqueiro através da CPUE $(\mathrm{kg}$. pescador $\left.{ }^{-1} \mathrm{dia}^{-1}\right)$ e um resumo das principais características da pesca do pacu (p. ex.: ambientes, e artes de pesca, períodos de safra e entressafra, etc.). Foram realizadas 306 entrevistas e destas 39 registraram captura do pacu.

\section{Resultados}

A categoria pacu, no período estudado, apresentou importância relevante nos desembarques pesqueiros do mercado Cai N'água. De acordo com o histórico da produção na região, no período entre 1977 e 1984 a 2004, o pacu contribuiu com $13,02 \%$ da produção anual total, com média de $86.585 \mathrm{~kg}$ (Tabela 1). Houve aumento considerável desta participação nos últimos anos, alcançando em 2002 percentuais de 20,45 (138.327kg), a maior registrada para os anos estudados.
A produção anual do pacu em Porto Velho, entre 1985 e 2004, quando relacionada à variação mensal do nível hidrológico do rio Madeira sugere que as variações apresentadas na produção pesqueira do pacu são influenciadas pela intensidade do pulso de inundação na região. As menores variações no nível hidrológico entre 1989 e 1990 poderiam ter influenciado as menores capturas do pacu nos anos subseqüentes. "Cheias" mais intensas como as dos anos de 1986, 1992, 1997 e 2001 precederam um aumento considerável na produção comercial da categoria pesqueira em questão (Figura 1). De acordo com os pescadores locais a "grande cheia", e conseqüente grande alagamento da planície de inundação, ocorre a partir da cota $16 \mathrm{~m}$.

TABELA 1: Produção anual total e da categoria pacu (kg) desembarcada no Mercado Cai N'água (Porto Velho-Rondônia), no período de 1977 e 1984 a 2004. (Fonte: 1977 Goulding; 1979; 1984 -89 Boischio, 1992; 1990-97 Doria et al., 1998).

\begin{tabular}{|c|c|c|c|}
\hline \multirow[b]{2}{*}{ Ano } & \multicolumn{2}{|c|}{ Produção (kg) } & \multirow[b]{2}{*}{$\%$} \\
\hline & $\begin{array}{l}\text { Total do mercado } \\
\text { de Porto Velho }\end{array}$ & Pacu & \\
\hline 1977 & 602.000 & 76.000 & 12,62 \\
\hline 1984 & 1.355 .500 & 125.900 & 9,29 \\
\hline 1985 & 1.067 .200 & 146.900 & 13,76 \\
\hline 1986 & 1.487 .500 & 119.900 & 8,06 \\
\hline 1987 & 1.140 .200 & 118.900 & 10,43 \\
\hline 1988 & 1.179 .300 & 101.400 & 8,60 \\
\hline 1989 & 927.500 & 91.000 & 9,81 \\
\hline 1990 & 614.080 & 85.650 & 13,95 \\
\hline 1991 & 742.260 & 74.850 & 10,08 \\
\hline 1992 & 391.604 & 33.109 & 8,45 \\
\hline 1993 & 1.060 .939 & 100.292 & 9,45 \\
\hline 1994 & 377.238 & 44.421 & 11,78 \\
\hline 1995 & 490.588 & 80.862 & 16,48 \\
\hline 1996 & 483.582 & 58.122 & 12,02 \\
\hline 1997 & 997.636 & 67.321 & 6,75 \\
\hline 1998 & 566.804 & 72.317 & 12,76 \\
\hline 1999 & 528.970 & 86.048 & 16,27 \\
\hline 2000 & 438.589 & 54.887 & 12,51 \\
\hline 2001 & 782.534 & 51.868 & 6,63 \\
\hline 2002 & 676.540 & 138.327 & 20,45 \\
\hline 2003 & 575.420 & 110.974 & 19,29 \\
\hline 2004 & 491.581 & 55.161 & 11,22 \\
\hline Média & 665.008 & 86.585 & 13,02 \\
\hline
\end{tabular}




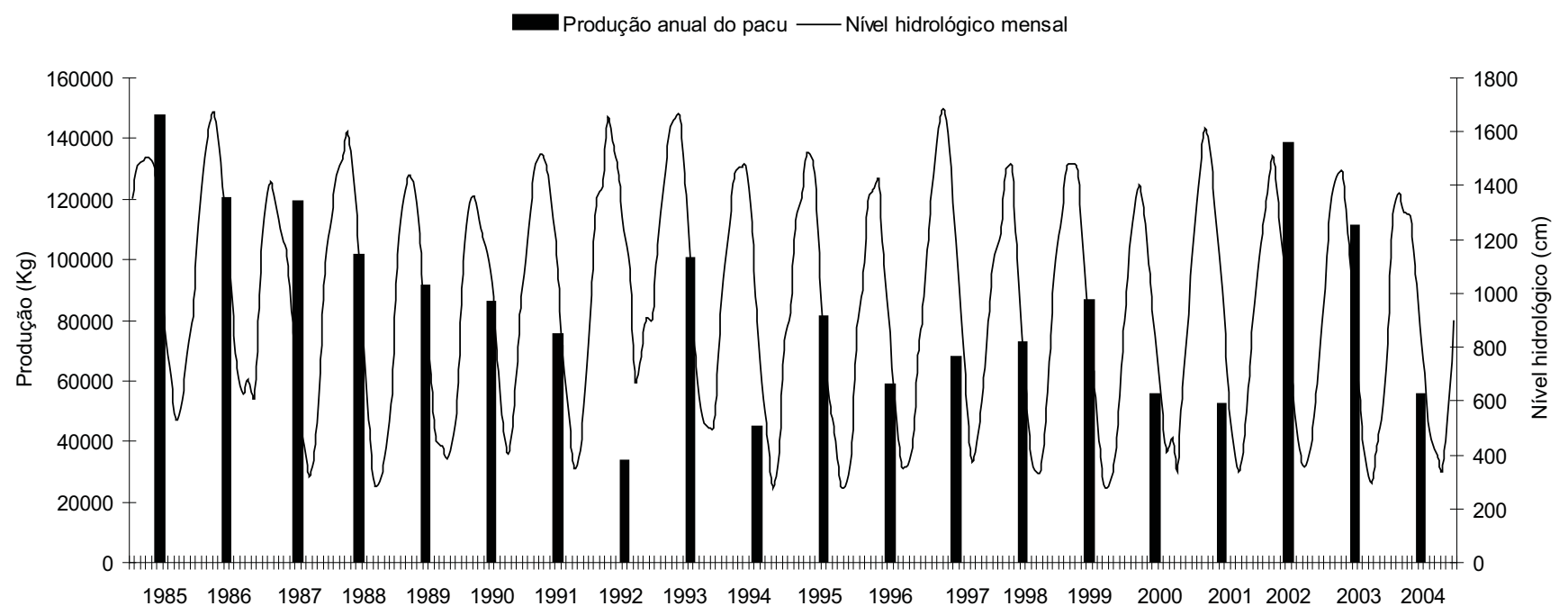

FIGURA 1: Valores anuais da produção pesqueira do pacu desembarcado no mercado pesqueiro Cai N'água em Porto Velho e variações mensais do nível hidrológico no período de 1985 a 2004.

Entre o período de 1990 e 2004, a produção pesqueira mensal variou de 0 (zero) a $42.366 \mathrm{~kg}$ (média= $5.772 \mathrm{~kg}$ ). Os maiores valores da produção mensal foram obtidos em períodos em que o nível do rio Madeira encontrava-se nas suas menores cotas hidrológicas indicando possivelmente maior capturabilidade nessa época, compreendendo principalmente os meses entre agosto e outubro (Figura 2).

A Captura Por Unidade de Esforço médio empregado pela pesca comercial para o pacu no período de novembro 2003 a fevereiro 2005, decorrente de 39 viagens com captura da categoria estudada, foi de 15 $\pm 21 \mathrm{~kg}^{*}$ pescador ${ }^{-1 *} \mathrm{dia}^{-1}$. As principais áreas de pesca estão localizadas na porção média e baixa da bacia do Madeira, sendo seus afluentes os principais pesqueiros (rios Jamari, Novo Aripuanã, Oropiara e Machado). Os rios foram os ambientes mais utilizados para a exploração desta espécie e as artes de pesca mais utilizadas pelos pescadores na captura dos indivíduos foram redes de lance e malhadeiras. Os indivíduos foram recrutados com comprimento médio de $19 \mathrm{~cm}$ (Tabela 2).

Do total dos 2.037 indivíduos que tiveram seus comprimentos aferidos no Mercado Cai N'água de Porto Velho, distribuídos nos anos de 1996/97, 2001 e 2004, o menor peixe capturado mediu $10 \mathrm{~cm}$ e o maior $34 \mathrm{~cm}$ (Figura 3).
TABELA 2: Súmula das características biológicas e da pesca do pacu, no mercado de Porto Velho.

\begin{tabular}{|c|c|}
\hline Característica & Observado \\
\hline Habitat (1) & Encontro de águas-lótico \\
\hline Áteos de necco & Médio e baixo Madeira \\
\hline $\begin{array}{l}\text { Area de pesca } \\
\text { Principais pesqueiros }\end{array}$ & $\begin{array}{l}\text { Rios: Jamari, Novo Aripuanã, Oro- } \\
\text { piara e Machado }\end{array}$ \\
\hline Ambiente de pesca & Rios \\
\hline & Artesanal \\
\hline Sistema de pesca & $\begin{array}{l}\text { Aparelhos de pesca: redes de lance, } \\
\text { malhadeira, caniço e arrastão }\end{array}$ \\
\hline Período de safra & Agosto - Outubro \\
\hline Período de entresafra & Dezembro - Março \\
\hline Recrutamento & Comprimento Médio: $19 \mathrm{~cm} \pm 3,69$ \\
\hline Crescimento & Amplitude: $14-20 \mathrm{~cm}$ \\
\hline Desova (1) & $\begin{array}{l}\text { Tipo: Total } \\
\text { Época: Outubro-fevereiro }\end{array}$ \\
\hline $\operatorname{Dieta}(2)$ & Sementes e frutos \\
\hline Parâmetros de rendimento & CPUE: $15 \mathrm{~kg}^{*}$ pescador ${ }^{-1 *} \operatorname{dia}^{-1}( \pm 21)$ \\
\hline $\begin{array}{l}\text { Total de viagens com cap- } \\
\text { tura do pacu, entrevistadas } \\
\text { no mercado no período de } \\
\text { Nov } / 03 \text { a Fev } / 05\end{array}$ & $\begin{array}{l}39 \text { viagens (totalizando } 471 \text { dias de } \\
\text { pescaria) }\end{array}$ \\
\hline
\end{tabular}

Fontes: (1) Ruffino e Isaac, 2000a; (2) Goulding, 1979.

A distribuição da freqüência relativa (\%) do pacu por classes de tamanho nos anos de 1996/97 apresentou predominância entre as classes de comprimento de 16-22cm. Em 2001 nota-se que o tamanho para o 


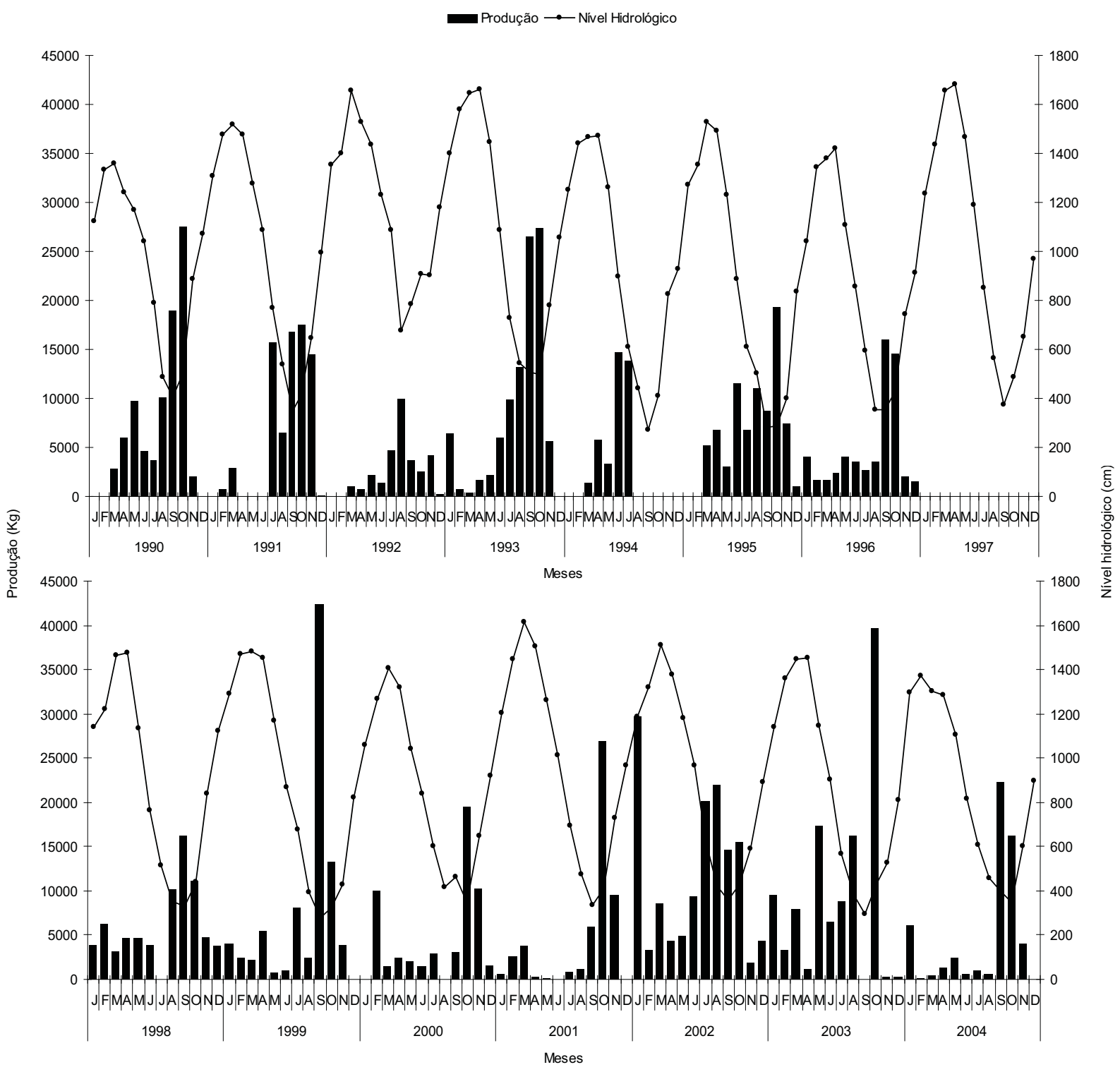

FIGURA 2: Valores mensais da produção pesqueira do pacu desembarcado no mercado pesqueiro Cai N'água em Porto Velho e variações mensais do nível hidrológico no período de 1990 a 2004.

recrutamento na pesca diminuiu, passando para classes de $12-20 \mathrm{~cm}$, e em 2004 observa-se um padrão semelhante na variação, com predominância das classes de $14-22 \mathrm{~cm}$ (Figura 3). A diferença nas classes de comprimento observada entre os anos de 96/97 para a 2001 e 2004 foi estatisticamente significativa $(\mathrm{P}<0,05)$ (ANOVA).

Houve maior captura na classe de comprimento de $18 \mathrm{~cm}$ nos períodos analisados, apresentando participação relativa de $34,76 \%, 28,66 \%$ e 22,29\%, para 96/97, 2001 e 2004, respectivamente.

\section{Discussão}

A categoria pacu apresenta grande relevância no âmbito das pescarias comerciais e de subsistência, apresentando alta representatividade na atividade pesqueira de toda Amazônia (Petrere Jr., 1978; Batista, 1998; Batista e Petrere Jr., 2003).

O histórico da produção na região e os resultados encontrados para a categoria demonstram também sua importância no desembarque pesqueiro no mercado Cai 
N'água de Porto Velho ao longo dos últimos 20 anos. $\mathrm{Na}$ década de 80 , as porcentagens de pacu em relação ao total desembarcado no Cai N'água giravam em torno de 10 a 13\%, aumentando gradativamente na década de 90 para valores próximos de $16 \% \mathrm{e}$, atualmente, a categoria chega a compor $20 \%$ do total desembarcado (Goulding, 1979; Santos, 1986/87; Boschio, 1992).

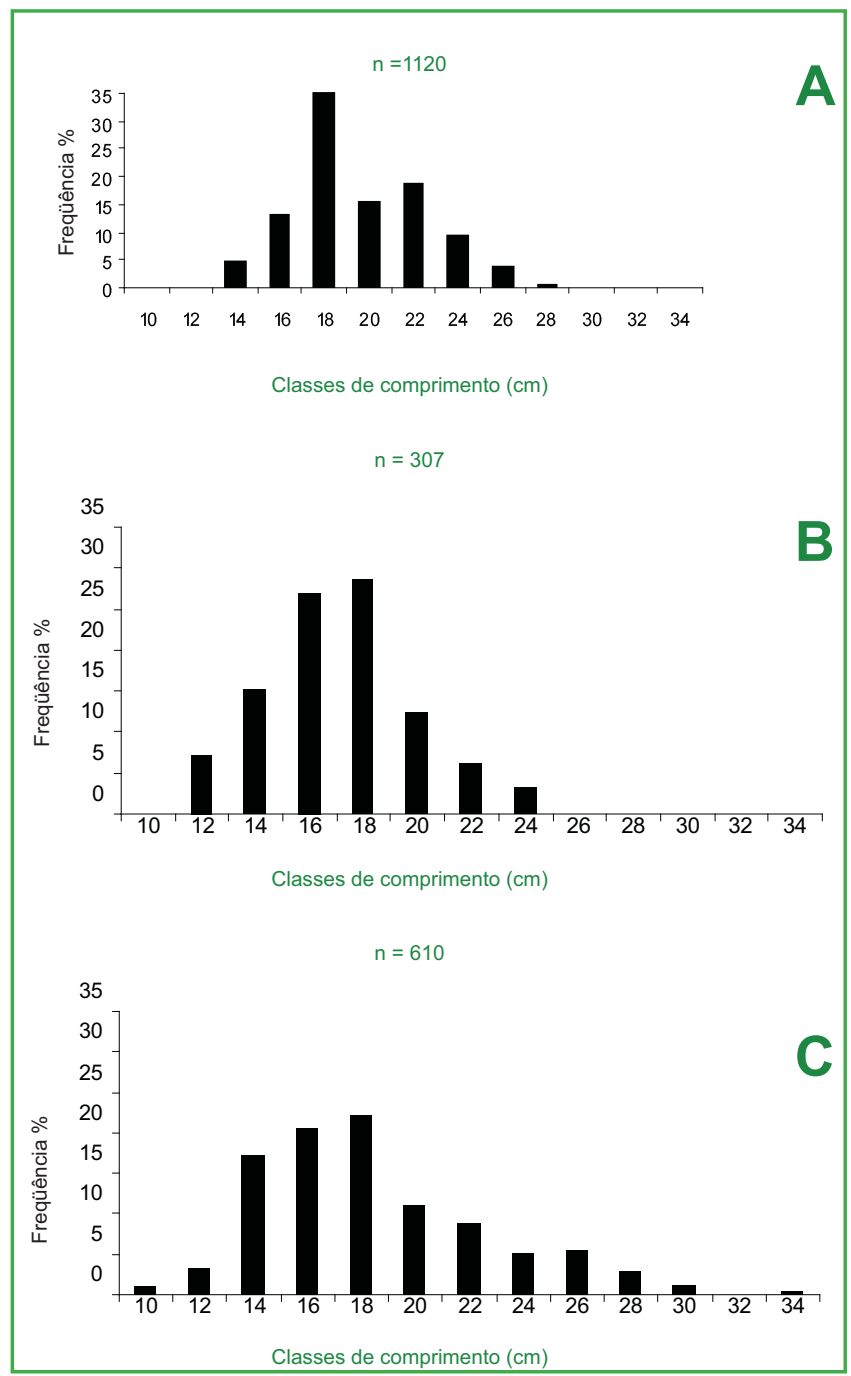

FIGURA 3: Distribuição de freqüência das classes de comprimento de exemplares de pacu capturados no Mercado Cai N'água em Porto Velho, nos anos de (A) 1996/1997, (B) 2001 e (C) 2004.

Esta elevada participação na produção pode ser devido ao maior esforço pesqueiro sobre espécies de pequeno porte, como constatado no alto valor de CPUE observado para o período $\left(15 \pm 21 \mathrm{~kg}^{*}\right.$ pescador $\left.{ }^{-1 *} \mathrm{dia}^{-1}\right)$. Fato semelhante foi observado nos desembarques regionais de Iquitos, onde tem ocorrido redução progressiva nas espécies de grande porte, acarretando incremento de outras espécies como Mylossoma spp e Triportheus spp. como alternativa de pescado (Tello e Bayley, 2001). Associado a esse incremento também está o alto rendimento, rápido crescimento e menor preço destas espécies. Isto também poderia estar ocorrendo na pesca do rio Madeira, onde peixes de menor valor comercial estão compondo com maior freqüência os desembarques (Leme, 2005). O aumento do esforço pesqueiro sobre a espécie pode estar provocando mudanças na estrutura da comunidade como observado na diminuição das classes de comprimento mais capturadas em 2001 e 2004 quando comparado à 1996/97. O que ressalta a necessidade de continuidade dos estudos para avaliar se está ocorrendo sobrepesca desta categoria.

$\mathrm{O}$ alto valor CPUE obtido pode estar relacionado à captura de indivíduos em grandes cardumes no momento da migração, o que facilita o recrutamento em grandes quantidades com poucos dias de esforço. Ressalta-se que esse valor de CPUE é superior ao observado para outras espécies Amazônicas. Comparando com a CPUE média do tambaqui (C. macropomum), que pertence a mesma família da espécie estudada, entre os anos de 1992 e 1993, foram obtido no baixo Amazonas valores entre $3 \mathrm{e}$ $14 \mathrm{~kg}^{*}$ pescador ${ }^{-1}$ dia $^{-1}$ (Isaac e Ruffino, 2000b).

As variações anuais na produção pesqueira do pacu podem estar também relacionadas a fatores ambientais, como à amplitude dos níveis fluviométricos. $\mathrm{Na}$ análise da representação gráfica da relação captura anual do pacu e cotas fluviométricas mensais, observa-se uma relação entre a produção e o regime hidrológico, demonstrando que há um aumento na produção em anos subseqüentes aos períodos de cheia que apresentaram altos valores nas cotas hidrológicos (acima de 16m). O contrário é observado em anos anteriores, onde a produção pesqueira do pacu decresce devido a cheias menos intensas no rio Madeira. Porém, a ausência de dados históricos sobre esforço pesqueiro não nos permite inferir se houve também uma variação no esforço empregado para a captura da espécie e chegar a resultados conclusivos sobre a importância das "grandes cheias" na produção pesqueira. Esta relação do nível hidrológico e a produção são comumente descritas pelos pescadores locais (observação pessoal). 
O alagamento de grandes áreas de várzea permite um maior sucesso reprodutivo devido a menor taxa de competição, predação e maior taxa alimentar. Além disso, quanto maiores os igapós e lagos centrais, maior será a taxa de recrutamento de indivíduos para a pesca (LoweMcConnell, 1999). Pode-se então admitir que os picos de produção pesqueira também estejam relacionados em grande parte à ecologia ou ao comportamento das espécies em seu ambiente natural, favorecendo as atividades da pesca (Santos, 1986/87).

O conhecimento empírico a respeito da variação sazonal do nível hidrológico e do movimento dos peixes na planície provocados por essa variação é outro fator que permite a seleção pelos pescadores dos locais para a pesca e dos aparelhos mais eficientes na captura de cada espécie, em cada fase do ciclo hidrológico (Barros e Ribeiro, 2005).

A análise das capturas mensais do pacu revelou maior produção nos meses de setembro e outubro, períodos que apresentam baixos valores das cotas fluviométricas. $\mathrm{O}$ aumento nas capturas no início da enchente também pode estar ocorrendo por essas espécies se encontrarem em grandes cardumes migrando para desova, fenômeno conhecido pelos pescadores que aproveitam para aumentar o esforço de pesca sobre a espécie, já que a captura é facilitada.

Baixa produção pesqueira nos meses em que os níveis dos rios estão mais altos e uma acentuada produção no início da vazante são características encontradas em toda Amazônia (Santos, 1986/87; Boischio, 1992; Isaac et al., 2004). Goulding (1979) relacionou este comportamento ao fato dos peixes se encontrarem dispersos na floresta inundada dificultando a captura em grande número, além da vegetação nesses ambientes limitar o uso de aparelhos de pesca.

A não captura ou o baixo nível de captura do pacu no mercado nos meses de dezembro e janeiro nos anos de 1999 a 2004 pode também ser devido ao período de proibição da pesca (período de defeso) que ocorre de novembro a fevereiro, que leva a conseqüente diminuição da atividade pesqueira na região.

O pacu desembarcado em Porto Velho é capturado na região do médio e baixo Madeira, contudo as pescarias ocorrem principalmente a jusante da cachoeira do Teotônio, nos afluentes do rio Madeira. Os rios são os principais ambientes explorados para a captura dos pacus, preferência que pode estar relacionada aos processos migratórios desta espécie, entre os afluentes da bacia.

A utilização de cada tipo de apetrecho depende diretamente da espécie-alvo e do ambiente de pesca escolhido (Isaac et al., 2004). Os resultados revelaram que os aparelhos comumente utilizados na pesca do pacu foram malhadeiras e rede de lance. O mesmo foi encontrado por Petrere, Jr. (1978) no estado do Amazonas. Outros autores também descrevem outros tipos de aparelhos para a pesca desta categoria, como a miqueira, o caniço, redinha (ou arrastão) e tarrafa (Petrere Jr. 1978; Goulding, 1979; Isaac et al., 2004).

Deve ser ressaltado o fato das espécies Myleus spp, Mylossoma spp e Metynnis spp. serem agrupadas na mesma categoria, "pacus", e que agrupamentos como estes podem interferir nas análises dos dados ecológicos e biológicos, ocasionando sérios problemas no fornecimento de subsídios técnico-científicos para a gestão dos estoques. Ressaltando a necessidade de se obter informações sobre a biologia pesqueira destas espécies separadamente.

Os resultados aqui apresentados são preliminares e apesar de descreverem a situação atual da exploração do pacu na região, não esgotam a necessidade de novos estudos sobre as espécies inclusas na categoria dos pacus.

\section{Agradecimentos}

Os autores agradecem à Colônia de Pescadores de Porto Velho Tenente Santana Z1 por disponibilizar os dados usados neste trabalho; aos pescadores pela disposição em contribuir com a pesquisa e a Furnas Centrais Elétricas pelo suporte financeiro na execução do projeto "Diagnóstico da ictiofauna e da pesca comercial na área sob influência dos Aproveitamentos Hidrelétricos Santo Antônio e Jirau", pelo qual os dados de 2003 e 2004 foram obtidos. 


\section{Referências}

Barros, J. F.; Ribeiro, M. O. de. 2005. Aspectos sociais e conhecimento ecológico tradicional na pesca de bagres. In: Fabré, N. N. \& Barthem, R. B. (coords). O manejo da Pesca dos Grandes Bagres. Piramutaba e dourada no eixo Solimões - Amazonas. Ibama/PróVárzea, Manaus, Brasil, p.32- 48.

Batista, V. S. 1998. Distribuição, dinâmica da frota e dos recursos pesqueiros da Amazônia Central. Tese de Doutorado, Instituto Nacional de Pesquisas da Amazônia/Fundação Universidade Federal do Amazonas, Brasil, 291pp.

Batista, V.S.; Petrere Jr., M. 2003. Characterization of the commercial fish production landed at Manaus, Amazonas State, Brazil. Acta Amazonica, 33 (1): 53-66.

Boischio, A. A. P. 1992. Produção pesqueira em Porto Velho, Rondônia (1984-89) - alguns aspectos ecológicos das espécies comercialmente relevantes. Acta Amazonica, 22 (1): 163-172.

Brasil de Souza, S. T. 2002. Recursos pesqueiros do Mercado de Porto Velho: estrutura das comunidades e características biológicas das cinco espécies de peixes mais explotadas no Mercado do Cai N'água, 1999 a 2001. Monografia de Bacharelado em Ciências Biológicas, Universidade Federal de Rondônia, Porto Velho, Brasil, 98pp.

Doria, C. R. C.; Torrente-Vilara, G.; Santos, G. M. 1998. Diagnóstico sócio-econômico-ecológico de Rondônia e assistência técnica pra formulação da segunda aproximação do ZSEE - fauna, Ictiofauna. Relatório Técnico. Consórcio Tecnosolo/DHV/Epitsa, Planafloro/RO, Porto Velho, Brasil, 81pp.

Goulding, M. 1979. Ecologia da pesca do rio Madeira. INPA, Manaus, Brasil, 154pp.

Goulding, M.; Barthem, R.; Ferreira, E. J. 2003. The Smithsonian Atlas of Amazon. Princeton Editorial Associates, Oklahoma City, USA, 253pp.

Isaac, V. J.; Ruffino, M. L. 2000a. Informe estatístico do desembarque pesqueiro na cidade de Santarém. In: Ruffino, M. L. (ed.). Recursos pesqueiros do médio Amazonas: biologia e estatística pesqueira. Ibama/PróVárzea, Manaus, Brasil, p.225-280.
Isaac, V. J.; Ruffino, M. L. 2000b. Biologia pesqueira do tambaqui, Colossoma macropomum, no baixo Amazonas. In: Ruffino, M. L. (ed.). Recursos Pesqueiros do médio Amazonas: biologia e estatística pesqueira. Ibama/PróVárzea, Manaus, Brasil, p.65-88.

Isaac, V. J.; Silva, C. O.; Ruffino, M. L. 2004. A pesca no Baixo Amazonas. In: Ruffino, M. L. (ed.). A pesca e os recursos pesqueiros na Amazônia brasileira. Ibama/PróVárzea, Manaus, Brasil, p.185-211.

Leme, Engenharia S.A., 2005. Estudo de Impacto Ambiental dos Aproveitamentos Hidrelétricos Santo Antônio e Jirau, Rio Madeira - RO. Capítulo IV - Área de Influência Direta dos Aproveitamentos Hidrelétricos de Jirau e Santo Antônio, Tomo B, Volume 5/8, Diagnóstico Ambiental da Área de Influência Direta, Meio Biótico, Ictiofauna e Recursos Pesqueiros. Relatório 6315 - RT - G90 - 001. Maio/2005. p IV-755 - IV-916

Lowe-Mcconnell. R. H. 1999. Estudos ecológicos de comunidades de peixes tropicais. Edusp, São Paulo, Brasil, 534pp.

Petrere Jr., M. 1978. Pesca e esforço de pesca no Estado do Amazonas. II. Locais de pesca, aparelhos de captura e estatísticas de desembarque. Acta Amazonica, 8 (Supl. 2): 1-54.

Petrere Jr., M. 1992. Pesca na Amazônia. Anais Seminário Internacional sobre Meio Ambiente, Pobreza e Desenvolvimento da Amazônia, Belém, Brasil, p. 72-77.

Santos, G. M. 1986/87. Composição do pescado e situação da pesca no estado de Rondônia. Acta Amazonica, 16/17: 43-84.

Sioli, H. 1968. Hydrochemistry and geology in the Brazilian Amazon region. Amazoniana, 1: 267-277.

Souza-Filho, P. W. M.; Quadros, M. L. E. S.; Scandolara, J. E.; Fi1ho, E. F. S.; Reis, M. R. 1999. Compartimentação morfoestrutural e neotectônica do sistema fluvial Guaporé-Mamoré-Alto Madeira, Rondônia - Brasil. Revista Brasileria de Geociências, 29 (4): 469-476.

Tello, S.; Bayley, P. 2001. La pesquería comercial de Loreto con énfasis en el análisis de la relación entre captura y esfuerzo pesquero de la flota comercial de Iquitos, cuenca del Amazonas (Perú). Folia Amazónica, 12 (1-2): 123-139. 